\title{
Experimental Investigation of Hydrogen Embrittlement in Industrial Steels
}

\author{
Kritik Sharma, Praveen Kumar \\ School Of Mechanical Engineering \\ VIT Vellore, Tamil Nadu, India, Email : kritiksharma31@gmail.com
}

\begin{abstract}
Steel is an alloy of iron and carbon and various other elements including chromium, nickel, manganese, vanadium, titanium, cobalt and tungsten. Steel is known for its high tensile and high fatigue strength and is employed hugely in buildings, weapons, and tool and automobile applications. In modern era, the production and consumption of steel has become a measure of a Nation's economic strength. Therefore the maintenance of steel and prevention from corrosion is a matter of worldwide concern. The chief corrosion method of steel is hydrogen embrittlement. Various experimental researches and theoretical investigations have been carried out to study about the mechanism of hydrogen embrittlement in industrial steels and its prevention.
\end{abstract}

Key words: Steel, Hydrogen Embrittlement, Corrosion, Crack growth

\section{INTRODUCTION}

Steel is one of the most important, adaptable and multi-functional of most of the materials. The development of steel can be treated as a synonym for the development of mankind. The foundation of the developed economies of today's world is laid on the superior strength and widespread uses of steel and today the production and application of steel is seen as a direct means of a nation's economic and industrial strength[1].

Steel can be further classified into several categories on the basis of different criterion. According to the amount of carbon present they can be classified into low, medium and high carbon steels. Depending on the alloying elements and their use they can be classified as tool, mild and high speed steel (HSS).

Steel has some unique characteristics like resistance to heat, ability to withstand hot and cold forming, resistance to wear, corrosion as well as being hard and tough, which makes it highly adaptive and weld able in every aspect of applications. The machining cost on steel is very low which allows steel to be manufactured in variety of shapes and areas of use. The resistance to corrosion property of materials is one of the most important factors implicating the long life in various applications [1-2]. The corrosion problem can arise due to physical as well as metallurgical parameters [2]. The main applications of low carbon and low alloy steels include the power and petrochemical industry. Majority of these steels present a problem of being susceptible to hydrogen attack when subjected to elevated temperatures and pressures during application. The term 'hydrogen embrittlement' is used to describe one of the most common effects of hydrogen in steels, which include loss of capacity to carry high loads, loss in mechanical properties like ductility, and enhanced fatigue cracking. [3].

The manufacturing facilities have been evolving various techniques with a basic motive of improving the characteristics of steel. There are more than two thousand grades of steel developed till now and thousand grades of which are high grade steels. There is an everlasting huge potential for improving new grades of steel offering a wide range of characteristics. Steel will always be one of the major elements for years to come. Thereby there is a need to improve the overall characteristics of this alloy so that it can be used with much more efficiency. This can be partly achieved by improving the alloy composition and thus enhancing its value. Aluminum is giving a tough competition to steel and will continue to give in nearby future. [4]. 
One of the major applications of steel is in different kinds of power plants. The major areas of application include boilers, pipe lines, and generator tubes, additional parts like screws fasteners, bolts, nuts, and supporting assemblies. [4-5]. All these selections are made from the close studies of their properties. These parts are subjected to fatigue or fracture failure due to hydrogen embrittlement [6-7].

The ductile to brittle transformation and fracture mechanics of materials is a complex process involving dynamic micro analysis. $[8,10]$. In today's energy-demanding society, there is an increasing trend toward gaining energy from more expensive sources. These sources constitute mainly fossil fuels from harsh environments and renewable energy sources, such as wind and wave power. Both of these approaches require modern materials with high loadbearing capacities, better tribological properties, and greater resistance against environmental effects such as corrosion and hydrogen embrittlement. All these properties can be met in one compound- the steel. The steel industry is continuously developing steels with superior mechanical properties for use in offshore oil platforms or wind mills. With increased mechanical strength, however, these steels become more prone to hydrogen embrittlement [11-14].

It's clear that hydrogen embrittlement remains to be one of the major contributors for corrosion of steels if embrittlement is seen as a mechanism which requires plenty of time and specific environmental conditions. Therefore studying this mechanism and identifying the various factors which either promotes or suppress the corrosion of steel is very necessary to increase the service life of steel in its various applications [15-19]. Rigorous studies and researches have been carried out till now in this field and we have gathered a lot of crucial information regarding this matter.

The chief constituent element of steel is Iron. Iron exists in 2 allotropic forms, the BCC or the Body Centered Cubic and the FCC or the Face Centered Cubic. The BCC form is known as Ferrite and the FCC structure is known as Austenite [20-21]. These allotropic forms exist at particular range of concentrations and temperature ranges. Due to interaction between the different allotropic forms and the alloying elements the steel is capable of showing its characteristics of high tensile strength [22]. In the case of pure iron, the crystal structure poses a very low resistance to the slipping mechanism, and therefore pure iron is soft, ductile, and formable[23]. Therefore this proves the need to include minor amounts of carbon and other inclusions within the iron which can act as hardening agents that prevent the movement of dislocations that are common in the crystal lattices of iron atoms [24-29].

Hydrogen damages prove to be an important factor in the degradation of metallic objects. Hydrogen Embrittlement (HE) of steels is extremely important topic for research due to huge application of steel in industrial applications and this article outlines the present level of studies which we have undergone in this area.

\section{EXPERIMENTAL STUDY MECHANISMS}

The prime motive is to study the mechanisms of hydrogen penetration in the steel and detailing about the crack propagation. Research has outlined different mechanisms for hydrogen propagation and crack growth. All have been studied vigorously and the major conclusions indicated that hydrogen enhances plastic behavior of materials under loading conditions [15, 30, 31]. IAN M. ROBERTSON et al. conducted the experiments which include in situ Transmission Electron Microscopy (TEM) straining experiments which were performed in a controlled gaseous hydrogen environment and further tested by several macro scale mechanical property tests.

B. Liao et al. conducted experiments for crack propagation and they reveal that the hydrogen shrinks the dislocation free zone (DFZ) by considerable amounts thereby leading to increase stress levels. Hydrogen also increases plastically deformed zone (PDZ) and makes the material plastic in nature under loading conditions [31-33].

V. I. Shvachko gave several facts and information about the reversible hydrogen embrittlement in metals and analyzed various aspects of this hydrogen embrittlement at the atomic, dislocation, microstructural, and macrostructural levels. They concluded that the defective structure of a metal plays a decisive role in all stages of reversible hydrogen embrittlement [34-38].

A.T. YOKOBORI conducted numerical analyses and gathered significant information about the phenomenon associated with the stress corrosion cracking and the elastic-plastic stress field which develops in the vicinity of the crack and the following interaction involving dislocations and 
hydrogen encircling a crack tip. The study included both the ductile and brittle materials. The results validated the experimental results obtained by other researchers. [39-40].

I. K. Pokhodnya et al. proposed a new procedure for testing and studying the various aspects of hydrogen embrittlement of steels. They explained that the present methods available for the quantitative determination of the sensitivity values of structural

\section{WELDING}

Steel is often subjected to shielded metal arc welding (SMAW) process. To investigate the resistance to corrosion, the mechanical properties and hydrogen embrittlement of steel from an electrochemical viewpoint, experiments were conducted with SSRT or the slow strain rate test method. The cathodic potential was kept constant. The SEM analysis was

\section{PIPELINE}

The pipelines are the lifeline of economy. Various resources like natural gas and oil are transported thousands of kilometers using pipelines. Hence the study of corrosion phenomenon in pipelines is very necessary. The initial study indicated that the ductility is reduced by the strain ageing of pipe metal which was composed of HSS (high strength steel) of strength category Kh80 (L. A. Efimenko et al.). At various temperatures the nature of steel was noted. The experiment concluded that the reaction of hydrogen with steel Kh80 after strain ageing leads to insignificant amount of embrittlement. This is because intergranular brittleness is developed in significant amount. [47-50].

In a different experiment a plastic welded joint of 17 G1S steel taken from a gas main was studied for its behavior of corrosion. The joint showed susceptibility to hydrogen embrittlement after electrolytic hydrogenation in acid solutions were carried out. (O. T. Tsyrul'nyk( et al.). The experiment also concluded that the procedure involving preliminary hydrogenation of specimens with welded joints under loading increased their susceptibility to embrittlement. [51-54].

Further in the study of steel bolts and nuts, experiment showed that anodically coated high strength steels (HSS) showed an increase in tendency towards hydrogen embrittlement. GIAN FRANCO et al. used a scratched Cd-coated AISI 4340 steel steels were not able to provide rigorous physical justification. They developed a new experimental procedure on the basis of the new physical model of hydrogen embrittlement which facilitates the determination of the degree of reduction in the brittle strength of a metal when subjected to the reversible influence of hydrogen. [41-44].

used to analyze the fracture surface (Seong-Jong Kim et al.). The major conclusion was that the post-weld heat treatment (PWHT) led to increased resistance to corrosion and better mechanical properties. Also the time-to-fracture and elongation were significantly decreased with decreasing the cathodic polarization potential. [1,2,45-46].

membrane which was coupled with different materials. Then they used a modified DevanathanStachurski permeation apparatus to measure the hydrogen uptake. In their study they concluded that in the presence of a crevice on steel sample, metals nobler than cadmium (Cd) highly enhance local hydrogen reduction on exposed steel areas, and increase the probability of corrosion and brittle fracture. This study guided the discontinuation of coupling of Cd-plated AISI 4340 steel bolts to the uncoated nuts comprising of noble passive alloys (like Inconel) [55-61].

Similar analysis was also conducted on zinc coated hub bolts to understand their mechanism of failure. The results showed that hydrogen embrittlement was the mechanism responsible of the failure of specimen. The chief features of the fracture surfaces were micropores on the grain surfaces and the yawning grain boundaries. The experiment also showed that poor baking treatment may lead to the partial removal of hydrogen from the sample and can initiate hydrogen embrittlement. [ $\mathrm{Na} \mathrm{Xu}$ et al. 62-67]

In a very recent experiment a thermal desorption analysis was conducted on X80 pipeline steel to measure the tracer hydrogen owing to that of lattice defects. (M. Hattori et al). The study showed that the amount of tracer hydrogen and the hydrogen embrittlement susceptibility were inversely proportional to the crosshead speed. A significant 
increase in the formation of strain-induced lattice defects immediately before the final fracture was also observed. This proved that the hydrogen enhances the formation of crystal defects just prior to the final fracture. The experiment also concluded that the final fracture occurred as a result of the conjugation of voids nucleated by the coalescence of several vacancy defects [68-74].

APIX70 steel is widely used as a material for construction of a pipeline for natural gas. Since the natural gas contains considerable amounts of hydrogen the pipeline is prone to hydrogen embrittlement. Study was conducted in order to analyze the effects of the hydrogen on the hydrogen embrittlement of air-cooled API X70 steel. (Dong-Su Bae et al.) The result showed that the tensile strength and yield were increased significantly and the elongation was considerably decreased for the sample

\section{NATURE}

The nature of hydrogen embrittlement from the perspective of chemical kinetics is also very crucial for understanding the various aspects related to it. The study on the two component continuum model with interaction between components helped to gather information about the kinetics of hydrogen embrittlement under loading conditions (D. A. Indeitsev et al.). the study on the model predicted loop dependence between stress and strain for

\section{STRENGTHENEING}

As mentioned in previous references the microstructure of the steel plays an important role in determining its resistance to corrosion and also hydrogen embrittlement. Addition of elements like nitrogen and silicon to the $\mathrm{Fe}-\mathrm{Cr}-\mathrm{Ni}$ system enhanced its resistance towards corrosion and cracking also. The experiment comprised of development of a new type of chromonickel stainless steel $(\mathrm{Fe}-\mathrm{Cr}-\mathrm{Ni}-\mathrm{N}-$ $\mathrm{Si}$ ) which was based on previously conducted researches. On the basis of the new system, two grades of steel were developed: 03X17H9AC2 and

\section{CONCLUSION}

Steel is by far one of the most important materials present on Earth. Its amount of consumption is seen as a measure of economic strength of a nation. India's consumption is $61 \mathrm{Kg}$ of steel per capita. With this enormous amount of steel consumption it becomes very necessary to prevent it from corrosion. The major contributor to this corrosion is the hydrogen embrittlement which affects all the areas of which was subjected to greater holding time in the vessel. The major conclusions comprised of the effect of hydrogen on changing the nature of fracture from ductile to brittle and also the formation of external cracks on the surface of specimen [75-81].

The existence of secondary phase particles like carbides also enhances the hydrogen embrittlement in steels. The carbide particles can act as trap sites for hydrogen atoms and, thus their presence has a profound impact on the kinetics and degree of hydrogen embrittlement of steels. V. G. Khanzhin et al. conducted experiments gather more information in this aspect using heat treatable $35 \mathrm{KhGM}$ and $33 \mathrm{KhM} 1 \mathrm{~F}$ steels as test samples with varying contents of carbide forming elements like molybdenum and vanadium and concluded that the carbides act as additional factors only while ductility and strength are the key factors which decide the kinetics of embrittlement [82-88].

materials containing dissolved hydrogen. This cleared the fact that the process of hydrogen embrittlement is a first order phase transition and takes place through nucleation of a new embrittled phase. Further thermodynamic equations and kinetic theories were also developed for hydrogen embrittlement which enabled us to calculate nucleation rate for embrittled phase [89-96].

03X14H9AC4 steel (V. V. Naumenko et al.). They are characterized by higher strength and corrosion resistance than for $03 \mathrm{X} 18 \mathrm{H} 11$ steel, which is widely used in oxidative conditions. The two types of steel samples were subjected to various heat treatment processes before tensile tests. The final conclusion of the experiment is that the addition of elements like nitrogen and silicon enhance the corrosion resistance of steel and also the austenite structure proves to be more stable and resistant to corrosion [97-101]

application including boilers, pipelines, bolts etc. We have come a long way in gaining the knowledge regarding this aspect. They have proved very beneficial as the cases of failure are decreasing. But still several researches are still going on in different parts of the world. Surely in the future we will be more efficient in using steel in the best possible 
manner decreasing its chances of embrittlement and

\section{REFERENCES}

1. Seong-Jong Kim and Kyung-Man Moon METALS AND MATERIALS International, Vol. 8, No. 4 (2002), pp. 395 401

2. O. Nishiyi, Corrosion Control 7, 13 (1964).

3. Y. KIM, Y.J. CHAO, MARTY J. PECHERSKY and MICHAEL J. MORGAN International Journal of Fracture (2005) 134:339-347

4. Hydrogen embrittlement in power plant steels, R K DAYAL and N PARVATHAVARTHINI Sadhana Vol. 28, Parts 3 \& 4, June/August 2003, pp. 431-451.

5. Akhurst K N, Baker T 1981 The threshold stress intensity for hydrogen-induced crack growth. J. Metall. Trans. A12: 1059-1070.

6. Hahn S J 1993 Hydrogen damage of waterwall tubes. Handbook of case histories in failure analysis (ed.) Khlefa A Easaklul (Materials Park, OH: ASM Int.) vol.2, pp 490-492

7. Gangloff R P, Wei R P 1977 Gaseous hydrogen embrittlement of high strength steels. Metall. Trans. A8: $1043-1053$

8. K.F. Yao, Q.Y. Tang, and N.P. Chen, TEM Observation on the Deformation Band of the Crack Tip Localization, Acta Metall. Sinica, Vol A27, 1991, p 395

9. R. Thompson, Dislocation Crack Interactions, Scr. Metall., Vol 29, 1986, p 1473

10. S. M. Ohr, Electron Microscope Study of Dislocation Emission from Cracks, Scr. Metall., Vol 20, 1986, p 151

11. Afrooz Barnoush, Masoud Asgari, Roy Johnsen, and Rune Hoel DOI: 10.1007/s11661-012-1462-4 The Minerals, Metals \& Materials Society and ASM International 2012

12. J Eastman, F Heubaum, T Matsumoto, and HK Birnbaum: Acta Mater., 1982, vol. 30, pp. 1579-86.

13. V. Ngomo, S. Fonlupt, L. Coudreuse, G. Baron, and E. Doucet: NACE International 2011, Publications Division, Houston, Texas, 2011.

14. A. Martinavicius, G. Abrasonis, A.C. Scheinost, R. Danoix, F. Danoix, G. Stinville, J.C. Talut, C. Templier, O. Liedke, S. Gemming, and W. Moller: Acta Mater., 2012, vol. 60, pp. 4065- 76.

15. Hydrogen Embrittlement Understood IAN M. ROBERTSON, P. SOFRONIS, A. NAGAO, M.L. MARTIN, S. WANG, D.W. GROSS, and K.E. NYGREN

16. R.P. Gangloff and B.P. Somerday: Gaseous Hydrogen Embrittlement of Materials in Energy Technologies: The Problem, Its Characterisation and Effects on Particular Alloy Classes, Woodhead Publishing Limited, Cambridge, U.K., 2012.

17. C. Skipper, G. Leisk, A. Saigal, D. Matson, and C.S. Marchi: in Effect of internal hydrogen on fatigue strength of type 316 stainless steel, B. Somerday, P. corrosion.
Sofronis, and R. Jones, eds., ASM International, Jackson Hole, WY, 2008, pp. 139-46.

18. R.P. Gangloff: in Proceedings of the 2008 International Hydrogen Conference-Effects of Hydrogen on Materials, B. Somerday, P. Sofronis, and R. Jones, eds., ASM International, Jackson Hole, WY, 2009, pp. 1-21.

19. G.M. Bond, I.M. Robertson, and H.K. Birnbaum: Acta Metall., 1988, vol. 36, pp. 2193-97.

$20 . \quad$ C.A. Zapffe and C.E. Sims: Met. Alloys, 1940, vol. 12 , pp. $145-51$.

21. H.K. Birnbaum and P. Sofronis: Mater. Sci. Eng., 1994, vol. 176, pp. 191-202.

22. R.A. Oriani and E.H. Josephic: Acta Metall., 1974, vol. 22, pp. 1065-74.

23. H.K. Birnbaum: J. Less-Common Met., 1984, vol. 104, pp. 31-41

24. I. Park, S. Lee, H. Jeon, and Y. Lee: Corros. Sci., 2015, vol. 93, pp. 63-69.

25. O. Kazum, M.B. Kannan, H Beladi, IB Timokhina, PD Hodgson, and S Khoddam: Adv. Eng. Mater., 2013, vol. 15 , pp. 1-3.

26. G. Hong and J. Lee: Metall. Trans. A, 1983, vol. 14A, pp. 156-58.

27. A.M. Brass and A. Chanfreau: Scripta Metall. Mater., 1990, vol. 24, pp. 499-04

28. S. Chou and W. Tsai: Mater. Sci. Eng. A, 1999, vol. A270, pp. 219-24.

29. D.P. Escobar, C. Minambres, L. Duprez, K. Verbenken, and M. Verhaege: Corros. Sci., 2011, vol. 53, pp. 3166-76.

30. J. Kacher, B. Eftink, B. Cui, and I.M. Robertson: Curr. Opin. Solid State Mater. Sci., 2014, vol. 18, pp. 227-43.

31. B. Liao, Y. Nan, Y. Hu, and D.T. Kang JMEPEG (1998) 7:100-103 ASM International

32. S.M. Ohr, An Electron Microscope Study of Crack Tip Deformation and Its Impact on the Dislocation Theory of Fracture, Mater. Sci. Eng., Vol 72, 1985, p 1

33. H. Kimura and H. Matsui, Mechanism of Hydrogen Induced Softening and Hardening in Iron, Scr. Metall., Vol 21, 1987, p 319S.

34. V. I. Shvachko, Micromechanical Aspects of Reversible Hydrogen Embrittlement, Materials Science, Vol. 36, No. 4, 2000

35. V. I. Tkachov, "Mechanism of the reversible action of hydrogen on the mechanical properties of steel," Fiz.Khim. Mekh. Mater., No. 4, 29-36 (1999).

36. V. K. Pokhodnya, V. I. Shvachko, S. A. Kotrechko, et al., "On the mechanism of the action of hydrogen on embrittlement of metals," Dokl. Akad. Nauk SSSR, 308, No. 5, 1131-1134 (1989).

37. I. K. Pokhodnya, V. I. Shvachko, S. A. Kotrechko, et al., "Influence of hydrogen on embrittlement of 
structural steels and welded joints," Avtomat. Svar., No. 5, 1-4 (1989).

38. V. I. Shvachko, "Reversible hydrogen embrittlement of steels as a physical phenomenon," Fiz.-Khim. Mekh. Mater., No. 4, 5-15 (1999).

39. A.T. YOKOBORI, JR. The mechanism of hydrogen embrittlement: the stress interaction between a crack, a hydrogen cluster, and moving dislocations International Journal of Fracture 128: 121-131, 2004.

40. Rui Husan Zhao, Shu-Hu Dai and Li, J.C.M.. International Journal of Fracture 3, 29. (1983)

41. K. Pokhodnya, V. I. Shvachko, S. A. Kotrechko, and Yu. Ya. Meshkov A New Method for Quantitative Determination of Sensitivity of Steels To Hydrogen Embrittlement Materials Science, Vol. 34, No. 4, 1998.

42. A.F. Svetlichkin and G. F. Raizman, "Degree of shear deformation as a parameter of steel embrittlement in moist hydrogen sulfide,"Fiz.-Khim. Mekh. Mater., 18, No. 5, 107-108 (1982).

43. O.N. Romaniv, G. N. Nikiforchin, and A. S. Krys'kiv, "Applicability of the criteria of fracture mechanics for estimation of hydrogen brittleness of high-strength steels," Fiz.-Khim. Mekh. Mater., 16, No. 6, 54-60 (1980).

44. V.V. Panasyuk, S. E. Kovchik, and G. I. Smoroda, "Methods of estimation of hydrogen brittleness of structural materials," Fiz.-Khim. Mekh. Mater., 15, No. 3, 5-17 (1979).

45. S. J. Kim, T. W. Park, I. O. Shim, J. H. Kim, Y. S. Kim, and K. M. Moon, J. Kor. Welding Soc. 19, 45 (2001).

46. W. von Baeckmann, W. Schwenkm, and W. Prinz, Handbook of Cathodic Corrosion Protection, vol. 72, p. 369, Gulf Publishing Company, Houston (1997).

47. L. A. Efimenko, V. Yu. Ilyukhin, V. M. Goritskii, G. R. Shneiderov, and A. M. Kulemin, TENDENCY TOWARDS STRAIN AGEING AND HYDROGEN EMBRITTLEMENT OF HIGH-STRENGTH STEEL Kh80 FOR MAIN PIPELINES Chemical and Petroleum Engineering, Vol. 44, Nos. 9-10, 2008.

48. O. V. Nosochenko,Yu. I. Matrosov, I. V. Ganoshenko, et al., "Properties of pearlite-free pipe steel of strength category Kh65 - 70 type $0.3 \mathrm{C}-1.5$ Mn $-0.09 \mathrm{Nb}$," Metallurg, No. 12, 30-33 (2003).

49. Yu. I. Matrosov et al., "Qualitative characteristics of low-pearlite steel 08G1B for large diameter gas pipelines," Stal', No. 12, 55-59 (2002).

50. P. Belyi, Yu. I. Matrosov, I. V. Ganoshenko, O. V. Nosochenko, and O. A. Bagmet, "Thick-sheet steel for gas pipelines of the Kh80 category," Stal', No. 5, 106-110 (2006).

51. O. T. Tsyrul'nyk et al. Susceptibility of A Welded Joint Of $17 \mathrm{~g} 1 \mathrm{~s}$ Steel In A Gas Main to Hydrogen Embrittlement Materials Science, Vol. 40, No. 6, 2004

52. V. D. Makarenko, V. A. Petrovskii, and V. Yu. Chernov, "Mechanism of hydrogen-induced stratification of pipe steels of oiland-gas pipelines," Fiz.-Khim. Mekh. Mater., 39, No. 6, 111-114 (2003).
53. I. Vasylenko, O. Yu. Shul'te, and O. I. Radkevych, "Influence of the chemical composition and technology of production of steels on their susceptibility to hydrogen and hydrogen-sulfide cracking," Fiz.-Khim. Mekh. Mater., 35, No. 4, 8-22 (1999).

54. O. I. Radkevych, "Influence of the chemical composition of welded joints of pipelines on the crack-growth resistance in hydrogen-sulfide media," Fiz.-Khim. Mekh. Mater., 35, No. 1, 95-102 (1999).

55. GIAN FRANCO LOVICU, COSTANZA COLOMBO, MASSIMO DESANCTIS, and RENZO VALENTINI, Hydrogen Uptake Enhancement and Accelerated Hydrogen Re-embrittlement of Cdplated AISI 4340 Steel Bolts Coupled with IN718 Nuts, DOI: $10.1007 / \mathrm{s} 11661-011-0880-\mathrm{z}$

The Minerals, Metals \& Materials Society and ASM International 2011

56. G. Chalaftris and M.J. Robinson: Corr. Eng. Sci. Tech., 2005, vol.40, pp. 28-32.

57. D. Figueroa and M.J. Robinson: Corr. Sci., 2008, vol. 50, pp.1066-79.

58. M. Nagumo, M. Nakamura, and K. Takai: Metall. Mater. Trans. A, 2001, vol. 32A, pp. 339-47.

59. E.M.K. Hillier and M.J. Robinson: Corr. Sci., 2003, vol. 46, pp.715-27.

$60 . \quad$ M.A.V. Devanathan and Z. Stachurski: Proc. R. Soc. London, Ser.A, 1962, vol. 270, pp. 90-102.

61. H. J. Grabke and E. Riecke: Mater. Tehnol., 2000, vol. 6, pp. 331-342.

62. $\mathrm{Na} \mathrm{Xu}$. Ning Ding . Junbo Shi . Weimin Guo . ChiMan Lawrence Wu Fracture Failure of Zinc-Plated Hub Bolts by Hydrogen Embrittlement, J Fail. Anal. and Preven. (2015) 15:464-469 DOI 10.1007/s11668015-9972-1

63. J.S. James, W.J. McBrine, Failures related to metalworking, in ASM Handbook, vol. 11: Failure Analysis and Prevention (ASM International, Materials Park, OH, 2002), pp. 178-226

64. M.T. Ferraz, M. Oliveira, Steel fasteners failure by hydrogen embrittlement. Cie^ncia e Tecnologia dos Materiais 20, 128-133 (2008)

$65 . \quad$ T.J. Carter, L.A. Cornish, Hydrogen in metals. Eng. Fail. Anal. 8, 113-121 (2001)

66. M.R. Louthan Jr, Hydrogen embrittlement of metals: a primer for the failure analyst. J. Fail. Anal. Prev. 8, 289-307 (2008)

67. C.J. Ye, W.B. Kan, Y.F. Li, H.L. Pan, Experimental study of hydrogen embrittlement on AISI 304 stainless steels and Rayleigh wave characterization. Eng. Fail. Anal. 34, 228-234 (2013)

68. M. Hattori, H. Suzuki, Y. Seko, and K. Takai, The Role of Hydrogen-Enhanced Strain-Induced Lattice Defects on Hydrogen Embrittlement Susceptibility of X80 Pipeline Steel, JOM, Vol. 69, No. 8, 2017 DOI: 10.1007/s11837-017-2371-1

$69 . \quad$ B. Saleem, F. Ahmed, M. Asif Rafiq, M. Ajmal, and L. Ali, Eng. Fail. Anal. 46, 157 (2014).

$70 . \quad$ B.T. Lu, J.L. Luo, and P.R. Norton, Corros. Sci. 52, 1787 (2010). 
71. Z.Y. Liu, X.Z. Wang, C.W. Du, J.K. Li, and X.G. Li, Mater. Sci. Eng. A 658, 348 (2016).

72. $\quad$ K. Takai, H. Shoda, H. Suzuki, and M. Nagumo, Acta Mater. 56, 5158 (2008).

73. T. Doshida, M. Nakamura, H. Saito, T. Sawada, and K. Takai, Acta Mater. 61, 7755 (2013).

74. R. Mastumoto, N. Nishiguchi, S. Taketomi, and N. Miyazaki, J. Soc. Mater. Sci. Jpn. 39, 182 (2014).

75. Dong-Su Bae1, Chi-Eun Sung, Hyun-Ju Bang, SangPill Lee, Jin-Kyung Lee, In-Soo Son, Young-Rae Cho, Un-Bong Baek, and Seung-Hoon Nahm, Effect of Highly Pressurized Hydrogen Gas Charging on the Hydrogen Embrittlement of API X70 Steel Met. Mater. Int., Vol. 20, No. 4 (2014), pp. 653 658

76. K. S. Kim, S. S. Kim, K. K. Park, K. M. Noh, and K. A. Lee, Korean J. Met. Mater. 51, 629 (2013).

77. Y. M. Kim, S. Y. Shin, H. Lee, B. Hwang, B. G. Park, S. Lee, and N. J. Kim, J. Kor. Inst. Met. \& Mater. 44, 223 (2006).

78. J. Moon, C. Park, and S. J. Kim, Met. Mater. Int. 18, 613 (2012)

79. H. S. Shin, K. H. Kim, U. B. Baek, and S. H. Nahm, Trans. Kor. Soc. Mech. Eng. A. 35, 1377 (2011).

80. D. Hardie, E. A. Charles, and A. H. Lopez, Corros. Sci. 48, 4378 (2006).

81. M. A. Arafin and J. A. Szpunar, Mater. Sci. Eng. A. 528, 4927 (2011).

82. V. G. Khanzhin, S. A. Nikulin, V. A. Belov, et al., "Hydrogen embrittlement of steels: II. Effect of the Strength," Deform. i Razrush. Mater., No. 8, 40-47 (2012).

83. V. G. Khanzhin, S. A. Nikulin, V. A. Belov, et al., "Hydrogen embrittlement of steels: I. An analysis of the hydrogen embrittlement kinetics from $\mathrm{AE}$ measurements," Deform. i Razrush. Mater., No. 8, 44-48 (2011).

84. V. G. Khanzhin and M. A. Stremel', "Quantitative information on fracture processes obtained by acoustic emission measurements," Mech. Term. Obrab. Mater., No. 5, 53-59 (2009).

85. M. Garet, A. M. Brass, C. Haut, and F. GutiérrezSolana, "Hydrogen trapping on non metallic inclusions in Cr-Mo low alloy steels," Corros. Sci. 39 (6), 1073- 1086 (1978).

86. S. Yuyama, T. Kishi, and Y. Hisamatsu, "Effect of environment, mechanical conditions and materials characteristics on $\mathrm{AE}$ behavior during corrosion fatique processes of an austenitic stainless steel," Nuclear Eng. and Design 81, 345-355 (1984).

87. V. G. Khanzhin, S. A. Nikulin, M. A. Stremel', and S. L. Namm, "Stage of static fracture of a cementite layer on acoustic emission measurements," Fiz. Khim. Met. Mater., No. 1, 89-92 (1990).
88. R. V. Herzberg, Deformation and Mechanics of Fracture of Structural Materials (Metallurgiya, Moscow, 1989).

89. D. A. Indeitsev and E. V. Osipova, Hydrogen Embrittlement

under Load as a First Order Phase Transition, Physics of the Solid State, 2009, Vol. 51, No. 9, pp. 19011906.

90. H. K. Birnbaum, in Hydrogen Embrittlement and Stress Corrosion Cracking, Ed. by R. Gibala and R. F. Hehemann (American Society of Metals, Metals Park, OH,United States, 1984), p. 21.

91. S. M. Myers, M. I. Baskes, H. K. Birnbaum, J. W. Corbett, G. G. DeLeo, S. K. Estreicher, E. E. Haller, P. Jena, N. M. Hohnson, R. Kirchheim, S. J. Pearton, and M. J. Stavola, Rev. Mod. Phys. 64, 559 (1992).

92. M. A. Baranov, M. Yu. Drozdov, V. G. Chudinov, and V. Ya. Bayankin, Zh. Tekh. Fiz. 70 (4), 46 (2000) [Tech. Phys. 45 (4), 427 (2000)].

93. D. A. Indeitsev, V. N. Naumov, and B. I. Semenov, Izv. Akad. Nauk, Mekh. Tverd. Tela, No. 5, 17 (2007).

94. D. A. Indeitzev and B. N. Semenov, Rev. Adv. Mater. Sci. 13, 85 (2006).

95. S. A. Kukushkin and A. V. Osipov, Usp. Fiz. Nauk 168(10), 1083 (1998) [Phys.-Usp. 41 (10), 983 (1998)].

96. G. Lu and E. Kaxiras, Phys. Rev. Lett. 94, 155501(2005).

97. V. V. Naumenko, G. A. Filippov, A. P. Shlyamnev, I. P. Shabalov, Resistance of Low_Carbon Nitrogen_Bearing Stainless Steel to Hydrogen Embrittlement and Slow Failure, Steel in Translation, 2013, Vol. 43, No. 6, pp. 388-393.

98. Naumenko, V.V., Shlyamnev, A.P., and Filippov, G.A., Mechanical and corrosion properties of $\mathrm{Fe}-\mathrm{Cr}-$ $\mathrm{Ni}-\mathrm{N}-\mathrm{Si}$ stainless steel, Probl. Chern. Metall. Materialov., 2010, no. 3, pp. 42-50.

99. Shakhpazov, E.Kh., Filippov, G.A., Shlyamnev, A.P., Naumenko, V.V., et al., Russian patent 2432413, Byull. Izobret., 2011, no. 30.

100. Mishin, V.M. and Filippov, G.A., Kinetics and physic-mechanical characteristics of the resistance of steel to slow failure, Deform. Razrush., 2007, no. 3, pp. 37-42.

101. Alekseeva, L.E., Naumenko, V.V., Filippov, G.A., and Shabalov, I.P., Influence of the nitrogen and silicon content on the stability of austenite and the resistance of low_carbon austenitic $\mathrm{Fe}-\mathrm{Cr}-\mathrm{Ni}-\mathrm{N}-\mathrm{Si}$ stainless steel to slow failure, Probl. Chern. Metall. Materialov., 2012, no. 2, pp. 55-60. 